\title{
Disaster Threats in the Gunungsewu Karst Area and Mitigation Efforts in the Framework of Disaster Risk Reduction Review of the Hydrological and Geomorphological Aspects
}

\section{Pipit Wijayanti, Rita Noviani}

Universitas Sebelas Maret

pipitwijayanti@staff.uns.ac.id

\section{Article History}

accepted 31/08/2020

\begin{abstract}
Karst is identical with arid, rocky areas and often drought disasters every year. Besides the drought, there are several hazards in the karst area. This study aims to review the various hazards that occur in the Gunungsewu Karst area and mitigation efforts that can be done. Multiple hazards are base on karst hydrological and geomorphological characteristics. This study is base on a literature review in several related studies, both in karst areas and in the research in the same area. Based on the results of the study, it was found that there are four types of hazards found in Gunungsewu Karst areas, namely drought, flooding, pollution, and collapse. In general, mitigation efforts that can be carried out are mapping hazards, monitoring, and increasing the capacity of people in karst areas. However, mitigation efforts are specifically made based on the type of hazards. It was done so that the existing hazards do not pose a disaster risk.
\end{abstract}

Keywords: Hazard, karst, Mitigation, Hydrology and Geomorphology

\begin{abstract}
Abstrak
Karst identik dengan daerah yang gersang, berbatu dan seringkali terjadi bencana kekeringan setiap tahunnya. Selain kekeringan, terdapat beberapa ancaman bencana di daerah karst. Penelitian ini bertujuan untuk mengkaji berbagai ancaman yang terjadi di Karst Gunungsewu beserta upaya mitigasi yang dapat dilakukannya. Penelitian ini berdasarkan tinjauan literatur pada beberapa penelitian, baik di daerah karst maupun pada penelitian di daerah yang sama. Berdasarkan hasil review didapatkan bahwa terdapat empat jenis ancaman yang terdapat di daerah Karst Gunungsewu, yaitu kekeringan, banjir, pencemaran dan collapse. Secara umum, upaya mitigasi yang dapat dilakukan adalah dengan memetakan ancaman bencana, memantau dan meningkatkan kapasitas masyarakat di kawasan karst. Akan tetapi, upaya mitigasi secara khusus dilakukan berdasarkan tipe ancamannya. Hal terebut dilakukan agar ancaman yang ada tidak menimbulkan risiko bencana.
\end{abstract}

Kata kunci: Ancaman, Karst, Mitigasi, Hidrologi, Geomorfologi

Social, Humanities, and Education Studies (SHEs): Conference Series https://jurnal.uns.ac.id/shes

p-ISSN 2620-9284

e-ISSN 2620-9292 


\section{PENDAHULUAN}

Bentuklahan karst terbentuk karena proses pelarutan yang intensif, dengan dicirikan oleh berkembangnya drainase bawah permukaan (Ford Williams, 1989). Litologi yang berupa batu gamping, mengakibatkan daerah karst sering kali merupakan daerah yang marginal. Daya dukung daerah karst relatif rendah sehingga kurang bisa diandalkan untuk mendukung kehidupan masyarakat daerah tersebut dari segi pertanian. Faktor yang membuat daya dukung daerah karst rendah yaitu: tanah pada daerah karst yang tipis, kekurangan air sehingga sedikit tanaman yang dapat berkembang di daerah tersebut. Kemampuan tanah mengikat air sebesar 112,92 termasuk dalam klasifikasi rendah (Wijayanti, et al, 2015).

Walaupun identik dengan daerah yang marginal, akan tetapi karst juga memiliki potensi dan fungsi yang strategis. Fungsi strategis tersebut dapat ditinjau dari hidrologis, klimatologi, biodiversity maupun obyek wisatanya. Sebaran karst sebesar $12 \%$ seluruh dunia (Ford and Williams, 1987), akan tetapi mampu menyediakan air minum sekitar $40 \%$ dan $25 \%$ dari populasi AS dan dunia (Ghasemizadeh et al., 2012).

Karst yang terbentuk karena proses pelarutan merupakan media yang potensi dalam menyerap karbon. Berdasarkan proses terjadinya, maka didalam karst dapat mencakup siklus karbon dan siklus air serta organik apabila memperhitungkan penggunaan lahan di atasnya. Haryono et al. (2009), menyatakan bahwa telah terjadi konsumsi karbon dioksida atau $\mathrm{CO}_{2}$ yang terjadi didalam proses denudasi karst yang berasal dari $\mathrm{CO}_{2}$ atmosfer dan $\mathrm{CO}_{2}$ tanah. Pengikatan karbon menjadi proses yang penting dalam karstifikasi, sehingga dianggap mampu memberi kontribusi dalam menyerapan karbon di atmosfer (Dreybrodt, 1988; Meybeck, 1993; Liu dan Zhao, 2000; Gombert, 2002).

Kawasan karst mempunyai potensi wisata yang besar, baik dipermukaan tanah maupun di bawah permukaan tanah. Proses pelarutan yang intensif di batu gamping menghasilkan ornamen - ornamen goa yang luar biasa. Goa Gong di Pacitan (sisi timur Karst Gunugsewu) merupakan goa terindah di Asia terkait dengan ornament yang terbentuk akibat pelarutan, Obyek tersebut menarik minat wisatawan yang besar sepanjang tahun.

Namun demikian, kawasan karst juga dikenal dengan daya tahannya (resilience) yang rendah terhadap perubahan atau gangguan (Gillieson, 1997), sehingga karst merupakan daerah yang rentan terhadap perubahan yang terjadi di daerah tersebut. Perubahan iklim dan aktifitas manusia dalam mengeksplore kawasan karst menjadi satu ancaman bagi keberlangsungan kawasan tersebut. Tulisan ini mencoba mengkaji berbagai ancaman bencana yang terjadi di karst terutama Kawasan Karst Gunungsewu beserta upaya mitigasi yang dapat dilakukan dalam perspektif hidrologi dan geomorfologi.

\section{METODE}

Lokasi penelitian di Karst Gunungsewu (Gambar 1). Karst Gunungsewu termasuk dalam karst tipe tropical karst, yang didominasi oleh batuan batu gamping tipe $\mathrm{Ca} \mathrm{HCO} 3$ (Adji et. al., 2016; Adji, 2010 dan Eiche et. al., 2018). Penggunaan Lahan didominasi oleh tegalan 31\%, sawah irigasi $22,7 \%$ dan permukiman $13,6 \%$. Semenjak tanggal 19 September 2015 oleh UNESCO ditetapkan sebagai Gunungsewu Global Geopark Indonesia. Daerah Karst Gunungsewu secara geomorfologis dibagi menjadi tiga, yaitu Karst Poligonal, Labirin dan Kubah Karst Sisa (Haryono dan Day, 2001).

Identifikasi ancaman bencana berdasarkan pada review literasi, baik daerah karst secara umum maupun di Karst Gunungsewu. Setelah diidentifikasi ancaman bencana yang dapat terjadi di karst Gunungsewu, maka dirumuskan upaya mitigasi yang dapat dilakukan. 


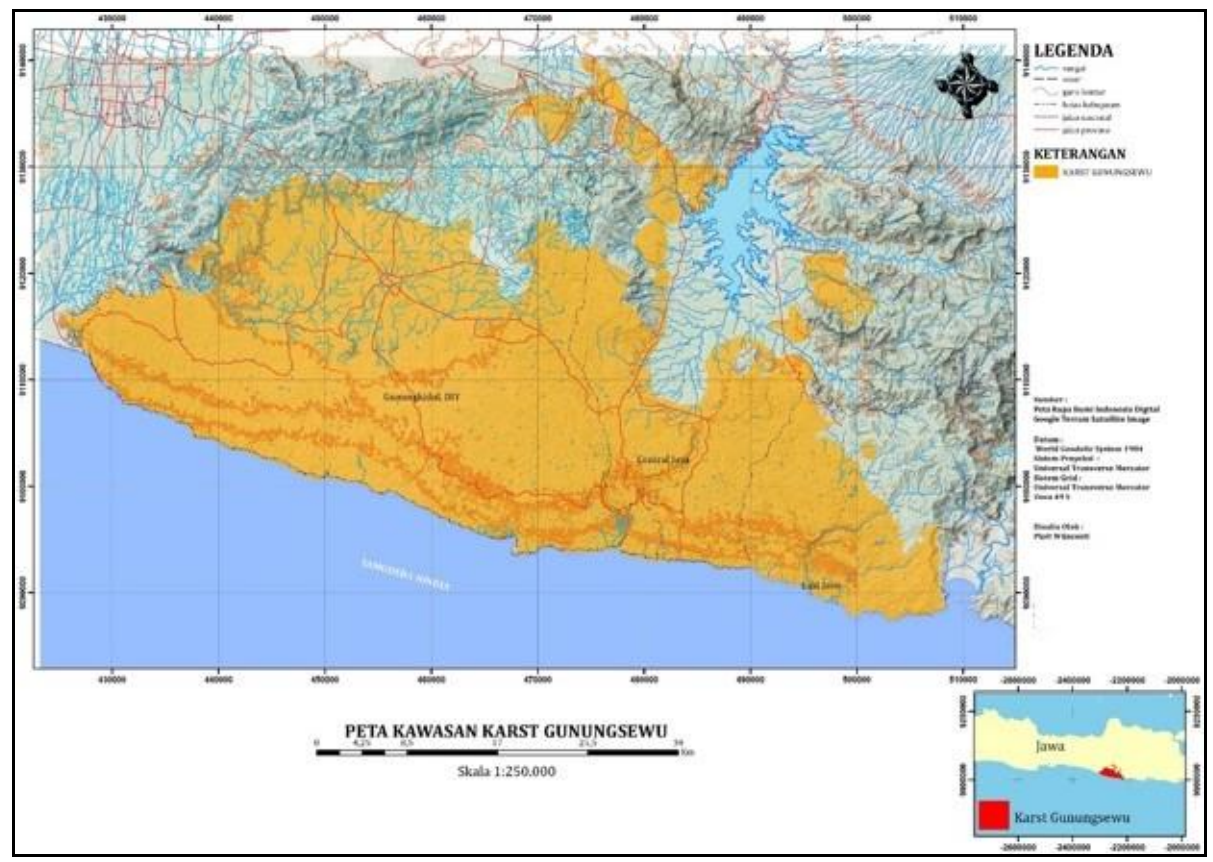

Gambar 1. Kawasan Karst Gunungsewu

\section{HASIL DAN PEMBAHASAN}

1. Ancaman kebencanaan di Karst Gunungsewu

Ancaman bencana didasarkan pada karakteristik hidrologis dan geomorfologinya. Berdasarkan kondisi hidrologis, maka ancaman bencana di daerah penelitian terdiri dari kekeringan, banjir dan pencemaran air tanah, sedangkan secara geomorfologi ancaman bencana berupa sinkhole.

\section{a. Kekeringan}

Kawasan Karst Gunungsewu dikenal sebagai wilayah rawan bencana kekeringan (Haryono et.al., 2009; Fatchurohman and Cahyadi, 2011; Cahyadi, 2016). Secara klimatologi daerah penelitian mempunyai hujan yang cukup sepanjang tahun, yaitu sebesar $2000 \mathrm{~mm}$ termasuk dalam klasifikasi sedang (Wijayanti, 2015). Dalam setiap tahun ada 7-8 bulan yang surplus, sehingga memungkinkan untuk memenuhi kebutuhan air domestik dan tanaman (Wijayanti, et al, 2015). Akan tetapi, kenyataan di lapangan, suplai air meteorologis tidak mampu memenuhi kebutuhan air bagi masyarakat di daerah karst. Hampir sepanjang tahun daerah karst mengalami kekeringan. Sampai Oktober 2019 terdapat 1300 jiwa terdampak kekeringan (BPBD Kab. Gunungkidul).

Neraca air di karst tropis mempunyai nilai evaporasi yang tinggi sebesar 76\% (Vestena L.R, 2007; Lestari, 2013 dan Wijayanti, et al., 2018). Kajian neraca air di DTA Kakap menunjukkan dari input air hujan yang jatuh tersebar menjadi evaporasi $76 \%$, debit mata air $22 \%$ dan $2 \%$ tersimpan sebagai simpanan air tanah (Wijayanti, et al., 2018). Surplus air hanya terjadi selama 2 bulan, selanjutnya merupakan bulan-bulan defisit. Hal tersebut menunjukkan bahwa faktor geologi menjadi faktor utama kekeringan. Batu gamping yang menyusun karst merupakan batuan yang kompak, akan tetapi air tanah dapat tersimpan pada akuifer yang terbentuk dari hasil pelarutan, sehingga akuifer karst sangat potensial. Namun demikian, simpanan tersebut seringkali berada jauh di bawah permukaan tanah, sehingga masyarakat sulit untuk mengekplorasi air. Mata air menjadi sumber air bersih utama yang mudah dijangkau, sehingga dapat dimanfaatkan oleh masyarakat. 


\section{b. Banjir}

Pemanasan global telah merubah distribusi dan intensitas air hujan yang jatuh ke permukaan bumi, sehingga mengakibatkan terjadinya perubahan iklim. Hal tersebut berimbas terhadap daerah karst. Respon daerah tangkapan air di karst terhadap hujan tergantung pada karakteristik dan perkembangan akuifer. Pada akuifer yang didominasi oleh aliran diffuse, maka responnya relatif lama apabila dibandingkan dengan akuifer yang didominasi oleh aliran conduit. Dalam hidrograf aliran, respon tersebut biasanya ditunjukkan dengan Time to Peak (TP). Pada aliran conduit, air hujan yang turun kan langsung direspon dengan cepat, terlebih apabila mempunyai system terbuka, dimana lorong yang terbentuk berhubungan langsung dengan permukaan tanah.

Dorongan aliran air yang besar ke dalam akuifer yang melebihi kapasitas akuifer akan menyebabkan banjir di permukaan. Hal tersebut terjadi karena aliran yang besar mendorong simpanan/aliran dasar di akuifer karst. Banjir airtanah yang terjadi di Karst Window Ngreneng terjadi akibat aliran air yang melalui lorong konduit melebih kapasitas penyaluran, sehingga air pada lokasi kajian naik melalui karst window dan membentuk danau pada doline (Cahyadi et al., 2019). Fenomena tersebut merupakan respon dari hujan ekstrim (>100 $\mathrm{mm} /$ hari) (BMKG, 2018) akibat adanya badai Cempaka.

Selain banjir pemukaan, respon yang cepat (Tp pendek) akan menjadi ancaman bagi obyek wisata yang berbasis aliran sungai bawah tanah. Kawasan karst Gunungkidul banyak dikembangkan obyek wisata berbasis masyarakat. Hal tersebut harus menjadi perhatian bagi pengelola obyek wisata. Wisata tubing atau jelajah goa yang terdapat sungai bawah tanah, harus memperhatikan respon daerah tangkapan air terhadap hujan agar wisatawan dapat memperoleh pengalaman wisata yang menarik dan aman. Fenomena tersebut menjelaskan walaupun rentan terhadap kekeringan di musim kemarau, akan tetapi kawasan karst juga rentan terhadap banjir pada musim hujan.

\section{c. Pencemaran}

Pembangunan pertanian, industri, perumahan, komersial dan kota dianggap sebagai sumber utama pencemaran air tanah dalam beberapa dekade terakhir (Fetter, 2001; Wakida dan Lerner, 2005). Meningkatnya permintaan oleh penggunaan perumahan, industri dan pertanian telah menyebabkan penipisan air tanah dan penurunan kualitas dibanyak daerah. Dari perspektif pembangunan berkelanjutan, dampak lingkungan, ekonomi dan sosial adalah konsekuensi dari pencemaran air di wilayah mana pun di dunia. Karenanya, perhatian yang seksama harus diberikan untuk melestarikan sumber daya air. Umumnya, terlepas dari sumber kontaminasi, patogen, senyawa organik (Lapworth et al., 2012), logam (Yao et al., 2012), dan senyawa anorganik lainnya (misalnya, nitrat, klorida) sering ditemukan di air tanah (Panagiotakis dan Dermatas, 2017; Vidal Montes et al., 2016).

Kontaminan yang paling umum ditemukan di Karst Gunungsewu adalah akibat aktifitas pertanian. Hal ini karena penggunaan lahan di kawasan karst didominasi oleh lahan pertanian (31\% tegalan dan $22,7 \%$ sawah irigasi). Penggunaan pupuk/pestisida dalam pengelolaan pertanian mengakibatkan pencemaran air tanah di Kawasan karst. Porositas sekunder yang berkembang intensif, dengan system terbuka (ponor) mengakibatkan proses pencemaran menjadi cepat dan tanpa penyaringan, sehingga air tanah di kawasan karst menjadi rentan untuk terjadinya pencemaran. Selain itu di daerah penelitian banyak ponor yang digunakan sebagai tempat pembuangan juga menjadi sumber pencemar domestic. 


\section{d. Sinkhole/ collaps}

Sinkhole/collaps disebabkan oleh berkembangnya drainase bawah tanah secara intensif akibat pelarutan. Perkembangan tersebut menyebabkan atap drainase permukaan berkurang kemampuan untuk menahan rongga di bawah permukaan, sehingga akhirnya akan runtuh. Collaps menjadi ancaman, ketika kawasan karst merupakan kawasan permukiman. Sering kali masyarakat tidak tahu bahwa d idalam permukaan bumi terdapat jaringan drainase yang berkembang intensif, sehingga mengancam kawasan permukiman. Selain itu, dibeberapa tempat terjadinya colleps juga dipengaruhi oleh fluktuasi air tanah (White, 1988).

Sinkhole yang terjadi di Kawasan Karst Gunungsewu, banyak terjadi di daerah di luar permukiman. Hal tersebut karena dominasi penggunaan lahan di Karst Gunungsewu berupa pertanian dan lahan terbuka, sedangkan permukiman hanya seluas 13 persen. Akan tetapi tidak menafikkan bahwa drainase berkembang intensif di bawah permukiman. Hasil penelitian di Goa Seropan, menunjukkan bahwa pengaruh struktur geologis sangat besar dan di sepanjang gua tempat penelitian terdapat beberapa tempat yang berpotensi runtuh, sehingga perlu mendapat perhatian serius dalam penanganannya (Nugraha, 2018)

\section{Upaya mitigasi terhadap Ancaman yang ada}

Mitigasi adalah serangkaian upaya untuk mengurangi risiko bencana, baik melalui pembangunan fisik maupun penyadaran dan peningkatan kemampuan menghadapi ancaman bencana (UU no 24, 2007). Upaya mitigasi yang dapat dilakukan dilakukan berdasarkan pada jenis ancaman yang ada. Berdasarkan jenis ancaman bencana yang ada di daerah karst Gunungsewu, maka upaya mitigasi yang dapat dilakukan disajikan pada Tabel 1 .

Tabel 1. Jenis ancaman dan upaya mitigasi

\begin{tabular}{|c|c|c|}
\hline Proses & Jenis Ancaman & Mitigasi \\
\hline \multirow[t]{3}{*}{ Hidrologi } & Kekeringan & $\begin{array}{l}\text { 1. Pemanenan Air Hujan } \\
\text { 2. Tanaman yang adaptif }\end{array}$ \\
\hline & Banjir & $\begin{array}{ll}\text { 1. } & \text { Karakteristik DTA } \\
\text { 2. } & \text { Pemantauan EWS }\end{array}$ \\
\hline & Pencemaran Air & $\begin{array}{ll}\text { 1. } & \text { Karakteristik DTA } \\
\text { 2. } & \text { Pemetaan } \\
\text { 3. } & \text { EWS }\end{array}$ \\
\hline Geomorfologi & Sinkhole & $\begin{array}{ll}\text { 1. } & \text { Pemetaan } \\
\text { 2. } & \text { EWS }\end{array}$ \\
\hline
\end{tabular}

Peran pemerintah, perguruan tinggi dan masyarakat dalam upaya mitigasi ancaman bencana di karst sangat penting. Pemerintah berkaitan dengan kebijakan dalam upaya mitigasi fisik di Kawasan karst dan menyediaan fasilitas untuk memperkuat sosialisasi dan edukasi kepada masyarakat. Perguruan tinggi dalam upaya mengetahui karakteristik Kawasan karst dengan penelitian dan publikasi, serta inventarisasi secara ilmiah. Hasil penelitian dan publlikasi tersebut digunakan sebagai dasar untuk memberikan edukasi kepada masyarakat. Masyarakat karst merupakan komunitas paling terdampak dari Kawasan karst. Sosialisasi dan edukasi memberikan pemahaman kepada masyarakat tentang karakteristik baik berupa potensi dan ancaman. Termasuk didalamnya tentang kearifan lokal yang telah berlangsung selama ini. Hal tersebut diharapkan pengelolaan kawasan menjadi tepat yang pada akhirnya menjadi lestari, bermanfaat secara berkelanjutan. 


\section{SIMPULAN}

Penting mengetahui ancaman yang terjadi di Kawasan karst mengingat peran penting kawasan karst tersebut. Upaya mitigasi dapat terlaksana apabila dilakukan bersama-sama antara pemerintah, perguruan tinggi dan masyarakat.

\section{DAFTAR PUSTAKA}

A Cahyadi. 2016. Peran Telaga dalam Pemenuhan Kebutuhan Air di Kawasan Karst Gunungsewu Pasca Pembangunan Jaringan Air Bersih. Geomedia, 14(2): 23-33

A Cahyadi, E Haryono, TN Adji, M Widyastuti, IA Riyanto, YT Nurteisa, H Fatchurohman, H Reinhard, RF Agniy, A Nurkholis, M Naufal, 2019, Groundwater Flooding due to Tropical Cyclone Cempaka in Ngreneng Karst Window, Gunungsewu Karst Area, Indonesia, E3S W eb of Conferences 125, 010 (2019) https://doi.org/10.1051/e3sconf/2019125010 ICENIS 2019

Adji, T.N., 2010, Variasi Spasial-Temporal Hidrogeokimia dan Sifat Aliran untuk Karakterisasi Sistem Karst Dinamis di Sungai Bawah Tanah Bribin Kabupaten Gunungkidul, DIY, Disertasi, UGM,

Adji T.N., Igor Yoga Bahtiar1., 2016. Rainfall-discharge relationship and karst flow components analysis for karst aquifer characterization in Petoyan Spring, Java, Indonesia, Environ Earth Sci (2016) 75:735, DOI 10.1007/s12665-016-5553-1

B Nugroho et al 2018, Potential collapse due to geological structures influence in Seropan Cave, Gunung Kidul, Yogyakarta, Indonesia IOP Conf. Ser.: Earth Environ. Sci. 106012007

Dreybrodt, W., 1988. Processes in Karst Systems. Springer, Heidelberg.

Eiche, E., Hochschild, M., Haryono, E., Neumann, T., 2016, Characterization of recharge and flow behaviour of different water sources in Gunung Kidul and its impact on water quality based on hydrochemical and physico-chemical monitoring, Appl Water Sci, doi: 10.1007/s13201-016-0426-z

Fatchurohman, H. and Cahyadi, A. 2011. Strategi Adaptasi Masyarakat Terhadap Bencana Kekeringan di Kawasan Karst Kecamatan Panggang, Gunungkidul. in Sudarmadji; Haryono, E.; Adji, T.N.; Widyastuti, M.; Harini, R.; Nurjani, E.; Cahyadi, A.; dan Nugraha, H. (Eds). 2011. Ekologi Lingkungan Kawasan Karst Indonesia. Yogyakarta: Deepublish.

Fetter, C.W., 2001. Applied HydroGeology, 4th edition. Prentice Hall, Inc., Upper Saddle River, NJ, USA.

Ford, D.C., Williams, P.W., 1989. Karst Geomorphology and Hydrology. Unwin Hyman, London

Ghasemizadeh, R., Hellweger, F., Butscher, C., Padilla, I., Vesper, D., Field, M., Alshawabkeh, A., 2012. Review: groundwater flow and transport modeling of karst aquifers, with particular reference to the North Coast Limestone aquifer system of Puerto Rico. Hydrogeol. J. 20 (8), 1441-1461. https://doi.org/10.1007/s10040-012- 0897-4.

Gombert, P., 2002, Role of karstic dissolution in global carbon cycle, Global \& Planetary Change; 33 (1/2), pp 177-185.

Haryono E., Day M., 2004, Landform differentiation within the Gunung Kidul Kegelkarst, Java, Indonesia. Journal of Cave and Karst Studies, v. 66, no. 2, pp. 62-69.

Haryono, E; Adji, T.N. and Widyastuti, M. 2009. Problems of Telaga (Doline Pond) in Gunungsewu Karst, Java, Indonesia. in White, W.B. (Ed). 2009. Proceeding 15th International Congress of Speleology, Vol. II. Texas: UIS 
Lestari Y., 2013, Studi Neraca Air dan Kualitas Air pada Sistem Hidrologi Mataair Beton untuk Konservasi Sumberdaya Air di Kecamatan Ponjong Kabupaten Gunungkidul, Tesis, Fakultas Geografi, UGM, Yogyakarta

Liu, Z., Zhao, J., 2000. Contribution of carbonate rock weathering to the atmospheric CO2 sink. Environmental Geology 39, 1053-1058.

Meybeck, M., 1993. Riverine transport of atmospheric carbon: sources, global typology and budget. Water, Air, and Soil Pollution 70, 443-463.

Vestena1 L. R., Kobiyama M., 2007, Water Balance in Karst: Case Study of the Ribeirão da, Brazilian Archives of Biology and Technology, Vol.50, n. 5 : pp. 905912

Wakida, F.T., Lerner, D.N., 2005. Non-agricultural sources of groundwater nitrate: a review and case study. Water Res. 39 (1), 3-16. https://doi.org/10.1016/j.watres. 2004.07.026.

Wijayanti P, Noviani R, Tjahjono G A 2015 Dampak Perubahan Iklim Terhadap Imbangan Air Secara Meteorologis dengan Menggunakan Metode Thornthwaite Mather untuk Analisis Kekritisan Air di Karst Wonogiri Geomedia

Wijayanti P., Haryono E., and Hadi M.P., 2018, Water Balance in Epikarst: Case study of Kakap Springs, the Eastern Karst of Gunungsewu, IOP Conf. Series: Earth and Environmental Science

Yao, Z., Li, J., Xie, H., Yu, C., 2012. Review on remediation technologies of soil contaminated by heavy metals. Proced. Environ. Sci. 16, 722-729. https://doi.org/ 10.1016/j.proenv.2012.10.099. 